\title{
The role of prior experience, intellectual property protection and communication on trust and performance in innovation alliances
}

\author{
R.J. Ruitenburg1, F.T.J.M. Fortuin ${ }^{2,3}$ and S.W.F. Omta ${ }^{2}$ \\ ${ }^{1}$ Department of Design, Production and Management, University of Twente, P.O. Box 217, 7500 AE Enschede, the Netherlands; \\ r.j.ruitenburg@utwente.nl \\ ${ }^{2}$ Department of Business Administration, Wageningen University; P.O. Box 8130, 6700 EW Wageningen, the Netherlands; \\ onno.omta@wur.nl \\ ${ }^{3}$ Food Valley NL, P.O. Box 294, 6700 AG Wageningen, the Netherlands; frances.fortuin@foodvalley.nl
}

OPEN ACCESS - RESEARCH ARTICLE

\begin{abstract}
An important concept in innovation literature is open innovation, where firms may use knowledge of other companies to develop new products or processes. However, there is a tension between the desire to be open, to profit from the knowledge of others, and the desire to be closed to prevent others from making use of the firms own profitable knowledge. Formal and non-formal intellectual property (IP) protection mechanisms may protect the company in an innovation alliance, but are often costly and may hinder flexibility and creativity. In the present paper the role of formal and non-formal IP protection arrangements and communication on the building and maintenance of trust and ultimately on performance has been investigated. A survey questionnaire was combined with semi-structured interviews of CEOs and R\&D managers of seven companies and two commercial research organizations in the seed sector, one agrifood company, one commercial research organization in the agrifood and one commercial research organization in the high-tech sector. Thirty-three innovation alliances were investigated in total. It was found that for companies active in an innovation alliance it is important to understand how prior experiences, IP protection and communication influence the level of trust in an alliance, and that the level of trust is positively related to innovation performance. Recommendations are given for open innovation managers how to make optimal use of the innovation potential of the alliance partner(s), by fostering communication within the alliance and by using formal IP protection arrangements as a platform to create trust within the alliance.
\end{abstract}

Keywords: open innovation, intellectual property protection, trust, innovation alliance, innovation performance

Copyright: ${ }^{\odot} 2014$ R.J. Ruitenburg et al. This is an open-access article distributed under the terms of the Creative Commons Attribution License, which permits unrestricted use, distribution, and reproduction in any medium, provided the original author and source are credited.

\section{Introduction}

Innovation can be defined as 'the implementation of a new or significantly improved product (good or service), process, marketing or organizational method ...' (OECD and EUROSTAT, 2005). Although this definition is very general and broad, it is clear that innovation is about improvement of the current situation by applying novel knowledge in novel ways. Novel knowledge often results from the interaction between actors (being people or companies or even countries) that differ largely from one another and do (therefore) not often interact with one another, e.g. Granovetters concept of weak ties (1973, 1983). In contrast to earlier research, which ascribe the practice of technological innovation to a corporate R\&D lab embedded in a vertically integrated commercialization infrastructure (e.g. Burgelman and Rosenbloom, 1997), the concept of Open Innovation, introduced by Chessbrough (2003) postulates that firms can and should use external as well as internal ideas, knowledge and technology if they want to be successful in innovation. Chessbrough and Rosenbloom (2002) emphasize that a prerequisite for successful commercialization of innovations, whether ranging from internal or external sources, is that these need to be aligned to the firms strategy and business model (cf. Fortuin, 2007; Zott, et al., 2011).

There are different ways in which firms access the knowledge and technology needed to complement their own internal resources available for innovations. Where some companies 
look for technology sourcing and acquisition (Arora et al., 2001; Nicholls-Nixon and Woo, 2003), others will go for strategic alliances with external suppliers of technology (Narula and Hagedoorn, 1999), or prefer a collaborative R\&D joint venture (Peck, 1986). Next to these more linear inbound and outbound modes of open innovation, Enkel et al. (2009) conceptualize the two-way interaction between firms and innovative actors outside the firm as the coupled mode of open innovation. The present paper focusses on the latter form of open innovation. In the review paper on open innovation, West and Bogers (2013) conclude that although the value creation potential of open innovation is consistently established in many studies, more research is needed on how value from such sources is captured.

The great challenge of this open innovation paradigm is how to retain value for one's company. How can one make sure that knowledge (or at least: its commercially applicable outcomes related to one's own business) remains exclusively one's own property - and thus valuable? How do companies protect knowledge so that they can enjoy the fruits of their own research (Omta and Van Rossum, 1999)? The opener one is, the larger the amount of new knowledge that can be accessed from others, but also the larger the chance that other firms will benefit from one's private research investments. A balance has to be found, and in the background lies the permanent pitfall for innovation: that firms lock themselves up in their R\&D-laboratories and do not share ideas and licenses that may be valuable to others and hence to the economy at large.

Formal intellectual property (IP) rights, confidentiality agreements and other kinds of institutional arrangements to prevent knowledge being stolen by other firms, may offer a solution here. But these arrangements are often expensive in terms of time, knowledge and money, and vulnerable for power differences in negotiations (Ozmel et al., 2013), which may make them especially difficult to apply for small and medium sized firms (SMEs). Furthermore, every arrangement has its specific characteristics that make it more or less suitable for different situations (Denolf, 2010). For example recipes cannot be protected by patents, but are very valuable for many producers of consumer goods in the agrifood sector. Another example is that patents are published in an open database, and can thus reveal important information about a company's strategic R\&D choices to competitors. Finally, these arrangements may turn out to put a lag upon innovation, as they are rigid and hence hinder creativity and flexibility, which is especially important in the case of innovation, which is per definition an uncertain process (Tepić et al., 2014).
A solution to this tension might be found in building (in case of a new alliance partner), or maintaining (during the alliance trajectory and in case of prior experience with a partner) trust that one's partner(s) will not abuse one's vulnerability when one is open with one's information. In this way, trust may substitute or compliment IP arrangements (Barney and Hansen, 1994). However, just knowing the role of trust is not enough, because trust is not a static concept, being either present or absent in a certain relationship. It is a dynamic concept: trust can be present in different levels, and the level of trust in a relationship may increase or decrease over time. Hence it is important to improve our understanding of the way in which trust develops. Once the factors leading to higher levels of trust are better understood, they can be used to advice managers how to foster trust in the uncertain world of innovation alliances.

The present study aims to improve our insight in the role of the interplay of past experience, IP protection and communication on trust and on the performance of innovation alliances. A survey questionnaire was combined with semi-structured interviews with the managers of 5 companies and of 5 commercial research organizations that are centrally involved in one or more innovation alliances. Questions were asked about possible previous experience with (successful or failed) innovation alliances, the IP protection methods used, the communication level and the building and maintenance of trust within the alliance and this was related to the perceived innovation performance of the alliance.

The remainder of this paper is organized as follows. Section 2 contains the theoretical background and the conceptual model underlying the empirical research carried out for the present study. In Section 3 a description of the research methods (questionnaire construction, data collection and data analysis) is given. In the results Section 4, a PLS model that shows the relations between the different constructs will be discussed. In Section 5 the conclusions and the limitations of the present study are presented and in Section 6 recommendations for innovation managers are provided.

\section{Theoretical framework}

Open innovation can be carried out in different governance forms, each with different characteristics related to the communication channels used for knowledge sharing, the incentives used to actuate the innovation partner(s) and the types of property rights used (Felin and Zenger, in press). One of the governance forms is called partnerships, alliances and CVC (corporate venture capital). This type is 
well suited in case of moderately complex problems that need significant knowledge exchange to be solved, while the information needed for a solution may be hidden from the problem owner (Felin and Zenger, in press). It is this type of governance that the present paper will investigate, as due to the problem complexity complete IP protection arrangements are impossible to achieve and communication between the partners is normally rich.

In an innovation alliance, as we will call this governance form, the actual (open) innovation is carried out. Here different companies with different expertise come together to share knowledge and experience, to make use of technologies of the other(s) and to create an innovation that would not have been feasible for them alone, or at least not at that speed, low costs and with that quality. However, in an innovation alliance collaborating parties are vulnerable. They open themselves up to the partner(s), and they share their technologies, knowledge and experience, but they do not want the partner(s) to benefit from it outside the purposes and boundaries of the innovation alliance itself. Furthermore, one can suffer from opportunism from the side of the other party, for example if a partner leaves the alliance before the results are reached, or does not invest in the alliance as agreed upon in advance. Hence, it is important to make sure that one can be secure of each other within the alliance. This should be guaranteed at the inception of the collaboration. Hence this research can be placed in the first phase of the model how firms profit from external innovations, as proposed by West and Bogers (2013), namely the phase of obtaining innovations from external sources.

In literature, different means to establish this security within collaboration have been discussed. The concepts of control (which we will call IP protection) and trust are often key in these discussions, while also communication between the partners seems to be of special importance. And not only may these factors influence each other (e.g. some argue that IP arrangements can be a prerequisite for trust), but they also may influence the innovation performance of the alliance itself, which of course is the ultimate goal of starting any innovation alliance, while IP and trust are only means towards this goal. To describe these different concepts and how they may be expected to influence each other, first the concept of trust will be introduced, than the relation between trust and IP and the role of prior experience and communication will be discussed. Finally concepts will be brought together in a framework of the innovation alliance.

Trust can be defined as 'the mutual confidence that no party to an exchange will exploit anothers vulnerabilities'
(Sabel, 1993, in Barney and Hansen, 1994: 176). Within the concept of trust we can make two important distinctions. The first is between psychological and behavioral perspectives on trust (Poppo, 2013). From a psychological perspective, trust is related to expectations and beliefs, in other words: attributes ascribed to the other partner. From a behavioral perspective, trust is observed in actual behavior and builds through ongoing cooperative interactions. The second distinction is between intentional and competence trust. Intentional trust is trust in the good intentions of the partner(s), especially related to opportunism. Competence trust is trust in the technical, cognitive, organizational and communicative competences of a partner (Klein Woolthuis et al., 2005: 814). The difference is thus between willingness and ability of the partner, and both may be difficult to grasp before one starts a collaboration.

Trust can be a source of competitive advantage (Barney and Hansen, 1994), as trust may substitute for costly governance costs to prevent opportunism; and trust may open new options for partners in the exchange, because these options would not be economically feasible if governance costs would have to be made to prevent opportunism. Furthermore, one could argue that in case of trust one can find new possibilities to cooperate, as one does not have to keep information away from the partner and new possibilities for synergy may be found. However, it is difficult to know if the partner is trustworthy, especially as (nearly) every company may fall prey to opportunism if the golden opportunity comes by, or if a bankruptcy is close (Nooteboom, 2006).

Our main interest lies in the role of prior alliance experience and IP protection on building trust. As Poppo (2013) shows in her review on interorganizational trust, prior experience with a partner (in her words 'the shadow of the past' (p.134)) has been shown to build trust. From a psychological perspective, this can be explained by trusting beliefs becoming stronger over time as these beliefs are confirmed. Here the psychological and the behavioral view on trust overlap, as these beliefs are confirmed by actual behavior in interactions with the partner.

The other important factor related to trust, IP protection, can be described as the process by which entrepreneurs can retain the uniqueness and value of their technological competences (MacEvily et al., 2004: 714), while 'intellectual property, often known as IP, refers to creations of the mind: inventions (patents), literary and artistic works, symbols, names, images, designs used in commerce' (EU Copyright Office; www.eucopyright.com/en/what-is-intellectualproperty). IP is important, as 'the owner of intellectual 
property can control and be rewarded for its use, and this encourages further innovation and creativity to the benefit of us all'. There is a big debate in literature about the relationship between trust and IP protection (or in literature terms: control, e.g. Poppo, 2013). Three different relations have been proposed (Klein Woolthuis et al., 2005). The first stream, stemming from transaction cost economics, regards IP as a basis for trust, as IP arrangements make opportunistic behavior more difficult. The second view conceptualizes IP in conflict with trust, as the setting up of IP arrangements might be regarded as a sign of distrust by the partner(s); IP arrangements may then even evoke conflict. Hence it is argued that IP negatively influences the level of trust. And thirdly, there is the notion that trust precedes IP arrangements and thus decreases the need for formal arrangements; the relation is embedded in trust.

Empirical evidence has shown that trust and IP can be both substitutes and complements to one another (Klein Woolthuis et al., 2005). On the one hand, trust can substitute for IP as a high level of trust has been found to reduce the need for contracts and monitoring (Das and Teng, 1998). On the other hand, trust and IP can be regarded to complement each other, as they are found hand in hand (e.g. Luo, 2002) or preceding contractual arrangements (Larson, 1992). Omta and Van Rossum (1999) found, in their study of twelve failed alliances, that distrust (and related: fear) were important in seven of these alliances. They even report that (in two cases) the IP negotiations between (specifically: European and American) partners were made much longer and more difficult because the American partners started the negotiations with 'corporate lawyers and fist-sized contracts' (Omta and Van Rossum, 1999: 6). However, the question remains how and why IP and trust sometimes complement and sometimes substitute each other.

An important distinction in IP protection is between formal and non-formal IP (Bönte and Keilbach, 2005). Building on Denolf (2010), in Table 1 we provide an overview of formal and non-formal IP protection methods. Denolf argues that IP protection methods are often used complementary to one another. Furthermore, industries differ in which IP protection methods they apply most. Here, the kind of innovation that one wants to protect is important. For process innovation confidentiality and for product innovation speed of gaining market share are often regarded as the most effective way to protect the innovation. Also the size of the company matters. Smaller companies tend more to speed, trade secrets and confidentiality and larger companies more to formal IP protection methods. It can be expected that the IP protection status of a company is of influence on the innovation performance of alliances, e.g. a company is expected to be more inclined towards cooperation with (potential) competitors if the company is sure one's own intellectual property is well protected. It may be expected that the experience a company has with previous alliances has an influence on future alliances, as well. For example, if a company has experienced a failed alliance, one may expect that this company will take more precautions to prevent a new failure by making more specific arrangements about IP and the deliverables.

Communication is also expected to play a role in the alliance, both in its performance as well as in the development of trust. This could be perceived as an intermediary role: it is not the communication itself that increases performance or trust, but it is the means through which novel knowledge travels or a trustworthy impression may develop. Communication may build trust, at least if the partner(s) is/are indeed trustworthy (Becerra and Gupta, 2003). Trust starts off with the general propensity to trust of the trusting party (the trustor) and the impression the trustor has about the party to be trusted (the trustee). More communication gives the trustor more information about the trustee and whether or not the trustee can be trusted, or in terms of Poppo (2013), knowledge-based trust is built. And indeed, Becerra and Gupta (2003) find a positive relation between the amount of communication and the evaluation of trustworthiness. Hence we expect to find that communication builds trust within an alliance. A different reason to assume a positive relation between communication and trust, is that communication offers a means for monitoring the arrangements made, or that one is less inclined to betray a person with whom one has a personal relationship (which is built by frequent contacts, Nilsson, 2008). Finally, communication is related to the

\section{Table 1. Formal and non-formal intellectual property (IP) protection methods.}

\begin{tabular}{ll}
\hline Non-formal IP & - confidentiality, trade secrets \\
protection & complexity of the product design \\
& or technology platform \\
& - quick standardization, speed of \\
& gaining market share \\
- & use of passwords \\
- & limitation of the internal mobility \\
& of personnel (glass walls) \\
- & patents, copyrights, trademarks, \\
& design rights \\
- & contracts (e.g. collaboration \\
& agreements) \\
- & non-competition clauses in \\
& contracts of employees
\end{tabular}


innovation performance itself. Here it is again useful to turn to Granovetter $(1973,1983)$. He shows, in his theory of the strength of weak ties, how communication is important in the spread of ideas. Novel information, which much more often leads to innovation than familiar ideas do, ranges most often from social groups relatively distant from oneself (as otherwise, the information would be familiar already). Hence, especially the relationships (the ties in a network) between people relatively distant and different from one another are important. As these people are more different, they are more likely to dwell in different social groups and hence to have access to different knowledge. Thus, these weak ties are thought to be a very valuable source of new ideas and thus of innovation.

The above considerations result in the conceptual model presented in Figure 1. Within the innovation alliance prior experience, IP protection and communication are expected to play important roles in building trust. As was argued, prior experience can be positively or negatively related to IP protection, depending if the company has positive or negative experiences in earlier innovation alliances in general, or with a specific partner in particular. As argued above, IP can also be positively and negatively related to trust, and it will therefore be analyzed separately if, and if so, why in certain instances the relation is positive, while in other instances it is negative. Intensive communication is expected to increase trust, and trust, in turn, is expected to be positively related to innovation performance.

\section{Research methods}

A survey questionnaire was combined with semi-structured interviews of CEOs and R\&D managers of seven companies and two commercial research organizations in the seed sector, one agrifood company, one commercial research organization in the agrifood and one commercial research organization in the high-tech sector. The number of employees in the Netherlands ranged from 20 to 500 full time equivalents (ftes) for the research organizations and two of the companies. In the other companies 500 to 1,200 fte were working. The R\&D intensity (R\&D fte/total fte) was high with a mean of $83.5 \%$ (SD: $19.9 \%$ ) for the research organizations and $25.2 \%$ (SD: $16.9 \%$ ) for the companies. Data were gathered about 33 innovation alliances: 29 successful and 4 failed alliances. Nineteen alliances were reported by the companies and 14 by the commercial research organizations.

The survey questionnaire was based on existing questionnaires, developed by Fortuin (2007), Tepić et al. (2014), Garbade et al. (2013a,c). Furthermore, questions

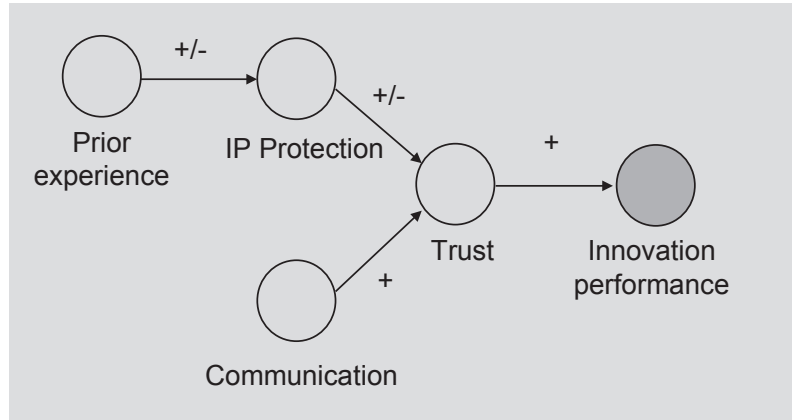

Figure 1. Conceptual model.

from the annual effect measurement of Food Valley NL (Omta and Fortuin, 2013), were used. Questions were raised regarding IP arrangements and the intensity of communication, the level of trust within the alliance and the innovation performance. The interview guide was extensively discussed with an expert in the field and tested in a pilot interview. The operationalization of the key concepts is presented below.

Prior experience was operationalized by asking the respondents if they had experienced alliance failure in the past. It can be expected that a company that has experienced a failed alliance will try to prevent alliance failure in the future, e.g. by making more tight IP arrangements. The respondents of 17 of the 33 innovation alliances reported to have experienced alliance failure.

To measure IP protection, three questions were asked, using 7-point Likert scales (ranging from 1 . not at all to 7 . to a very large extent) namely:

- In this alliance patent and/or technology mapping was used.

- At the start of the cooperation arrangements were made regarding:

- confidentiality;

- property rights of outputs and/or results.

The respondents have been asked to indicate the importance for the company of each formal and non-formal IP protection mechanism as shown in Table 1 using 7-point Likert scales (ranging from 1 . not at all important to 7 . very important). Only the respondents of seven companies and two commercial research organizations could answer (part of) this question, so $\mathrm{n}$ is lower than 33 (Table 7).

Communication has been measured by asking the respondent how often there has been contact between employees of their company and employees of any of the partners in the alliance, divided over three types of 
media: e-mail, face-to-face and telephone. The level of communication was measured using a 7-point Likert scale, ranging from 1 . more than once a week to 7 . less than once a year. Trust was measured using four 7-point Likert scale questions (ranging from 1. completely disagree to 7 . completely agree), namely:

- In a new project I certainly want to cooperate with this partner again.

- We would be willing to do extra investments in this alliance, if this might be needed.

- In this alliance opportunism appears/appeared to be a problem.

- This partner always does what he promises.

Innovation performance was measured using two 7-point Likert scaled questions (ranging from 1. not at all to 7 . very much):

- In this alliance products were developed that were new to the company.

- In this alliance new production processes were developed that are new to the company, or these have been greatly improved.

Data collection started with contacting the respondents, and sending them the interview guide in advance. The interviews were thoroughly prepared, by reading information from the website of the organization, reading annual reports and by looking up public data, e.g. in the patent database. The interviews took 1 to 1.5 hours; detailed transcripts of the interviews were made, and were sent to the respondents to be checked. With their remarks the final version of the transcript was made.

The quantitative data are based on the 7-point Likert scale questions, except for the general data about the company (e.g. turnover, employees, number of patents). As it turned out that the data were not normally distributed, nonparametric methods of analysis were used. The data were investigated on their general characteristics, using explore and descriptive statistics in SPSS. The correlations between the formal and non-formal IP protection mechanisms and the different trust variables were analyzed using Spearman Rank correlation.

The conceptual model was tested by PLS modeling (Garbade, 2013b) using t-tests of the path coefficients (between the latent variables) and the outer loadings (the loadings of the constituting variables on the latent variables). The significance of the interaction effects uncovered with PLS was tested with bootstrapping, a cross-validation method. It is a resampling procedure, which yields the same number of cases as in the original sample. As the bootstrapping is based on trial and error it gives slightly different results every time it is used for the same model. The number of resamples was chosen to be 5,000, far exceeding the 200 indicated as minimum.

\section{Results}

The conceptual model presented in Figure 1 describes the relation between prior experience, communication, trust, IP arrangements and innovation performance. As discussed in Section 3, to test the validity and reliability of the model we followed Garbade et al. (2013b). For the Individual item reliability again each variable should have a cross-loading of at least 0.7 to its latent variable and all indicators should have their highest cross loading on the latent variable they are connected to.

In Table 2 the cross loadings can be found. It becomes clear that every indicator has a cross-loading of minimally 0.83 to its own variable, and hence the 0.7 criterion has been fulfilled. Also there are no indicators with a higher cross loading on another latent variable than the one they belong to (although for communication - face-to-face the cross loading to the latent variable Communication is as high as Trust, which may show the special importance of face-to-face contact for building trust). The convergent validity of the latent variables, the internal consistency, can be measured using the composite reliability measure. Hulland (1999) proposes a cutoff point: 0.7 is the minimum. As can be seen in Table 3, all three latent variables score far above this minimum.

The discriminant validity is a measure to see if the different latent variables in the model do really differ from one another. The square root of the average variance extracted (AVE) should be higher than the latent variable correlations. Furthermore, the AVE should be 0.5 or higher.

Table 4 shows that the AVEs are far above 0.5. However, two correlations (underlined) are equal or higher than the SQRT AVE of one of the latent variables they belong to. The first is the correlation between Trust and IP, which is as high as the SQRT AVE of IP. As both are related in the model (IP loads on Trust) a correlation could have been expected. However, this correlation should not be higher (or here: as high) as the cohesion of the contributing variables in the latent variable IP. However, it has not been chosen to take the variable with the lowest cross loading in IP (IP protection - property rights) out of this construct, as more variables loading on a construct is important for the quality of the model (as this adds more variance to be explained to the model). The second, more problematic, case is the high 
Table 2. Cross loadings performance model (in black cross loadings of the indicators on the latent variable they are connected to; e.g. the latent variable IP arrangements is based upon 3 indicators with cross loadings ranging from 0,83-0,94).

\begin{tabular}{|c|c|c|c|c|c|}
\hline & Experience & IP arrangements & Communication & Trust & Performance \\
\hline Prior experience - experience with a failed alliance & 1.00 & 0.83 & 0.70 & 0.70 & 0.73 \\
\hline IP protection - patent/technology mapping & 0.60 & 0.84 & 0.72 & 0.72 & 0.77 \\
\hline IP protection - confidentiality & 0.80 & 0.94 & 0.87 & 0.87 & 0.91 \\
\hline IP protection - property rights & 0.75 & 0.83 & 0.60 & 0.69 & 0.73 \\
\hline Communication - e-mail & 0.60 & 0.74 & 0.96 & 0.81 & 0.77 \\
\hline Communication - face-to-face & 0.75 & 0.91 & 0.93 & $\underline{0.93}$ & 0.97 \\
\hline Communication - phone & 0.64 & 0.75 & 0.97 & 0.86 & 0.81 \\
\hline Trust - cooperate again & 0.58 & 0.70 & 0.88 & 0.90 & 0.78 \\
\hline Trust - extra investments & 0.71 & 0.90 & 0.87 & 0.98 & 0.97 \\
\hline Trust - keeping promises & 0.71 & 0.90 & 0.87 & 0.98 & 0.97 \\
\hline Performance - new products & 0.67 & 0.88 & 0.81 & 0.93 & 0.97 \\
\hline Performance - new processes & 0.75 & 0.91 & 0.93 & 0.93 & 0.97 \\
\hline
\end{tabular}

Table 3. Composite reliability of the performance model.

\begin{tabular}{ll}
\hline & Composite reliability \\
Prior experience & 1.00 \\
IP protection & 0.90 \\
Communication & 0.97 \\
Trust & 0.97 \\
Performance & 0.97 \\
\hline
\end{tabular}

correlation between IP and Performance. This indicates that it might improve the model by connecting IP protection to Performance. This was done and it indeed results in a significant path coefficient $(0.41, \mathrm{t}$-value $=2.21)$, while also the path between Trust and Performance remains significant (0.59, t-value=3.38).
The conceptual model has been tested using PLS. The t-values have been calculated using a bootstrapping procedure of 5,000 samples. All outer loadings are highly significant (Table 5 - the lowest value is $\mathrm{t}=7.98$ ).

Figure 2 shows the PLS test of the conceptual model. It shows that significant and positive relationships are found between Failed alliance experience and IP protection, between IP protection and Trust (although only at alpha $=0.05$ for a one-sided test), between Communication and Trust and, finally, between Trust and Innovation Performance. In the Table in the Appendix more precise information is given.

The fit of the PLS model has been evaluated using the $\mathrm{R}^{2}$ value. Three of the constructs have an $\mathrm{R}^{2}$ value (which measures how much of the variance of all contributing and latent variables on the variable is). Table 6 shows that all correlations are rather strong; IP has the weakest fit $\left(\mathrm{R}^{2}=0.69\right)$, which is still good. Furthermore, most of the

Table 4. Discriminant validity of the performance model (in gray the latent variable correlations).

\begin{tabular}{|c|c|c|c|c|c|c|c|}
\hline & Performance & Communication & Experience & IP & Trust & SQRT AVE & AVE \\
\hline Performance & 1.00 & & & & & 0.97 & 0.95 \\
\hline Communication & 0.90 & 1.00 & & & & 0.95 & 0.91 \\
\hline Prior experience & 0.73 & 0.70 & 1.00 & & & 1.00 & 1.00 \\
\hline IP protection & $\underline{0.92}$ & 0.85 & 0.83 & 1.00 & & 0.87 & 0.76 \\
\hline Trust & 0.95 & 0.91 & 0.70 & $\underline{0.87}$ & 1.00 & 0.96 & 0.92 \\
\hline SQRT AVE & 0.97 & 0.95 & 1.00 & 0.87 & 0.96 & & \\
\hline
\end{tabular}


Table 5. $t$-values of the outer loadings.

\begin{tabular}{|c|c|c|c|}
\hline & Sample mean & Standard error & t statistics \\
\hline IP protection - patent mapping & 0.83 & 0.08 & 10.83 \\
\hline IP protection - confidentiality & 0.95 & 0.03 & 29.95 \\
\hline IP protection - property rights & 0.82 & 0.10 & 7.98 \\
\hline Communication - e-mail & 0.95 & 0.03 & 29.15 \\
\hline Communication - face-to-face & 0.93 & 0.04 & 25.14 \\
\hline Trust - cooperate again & 0.90 & 0.06 & 15.61 \\
\hline Trust - extra investments & 0.98 & 0.03 & 38.58 \\
\hline Performance - new products & 0.97 & 0.02 & 40.92 \\
\hline Performance - new processes & 0.97 & 0.04 & 27.60 \\
\hline
\end{tabular}

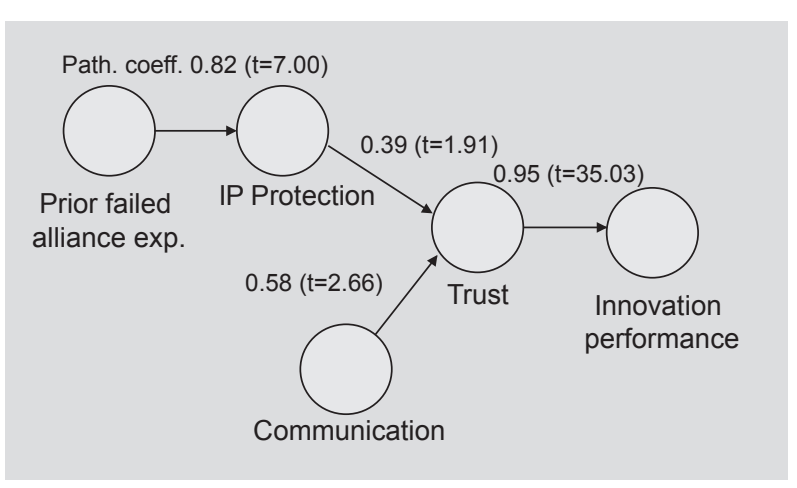

Figure 2. PLS test of the conceptual model.

variance in Performance has been explained, even though IP has not been connected to this construct, which shows that the model has not suffered too much from leaving out this possible linkage. The relation between Trust and Performance has been shown in this model. It turns out that this relation is strong (path coefficient $=0.95$ ) and highly significant ( $t$-value=35.03). Also if a path between IP and Performance would be included, still the influence of Trust is higher than the contribution of IP. Hence, the importance of trust in an innovation alliance should be emphasized.

It has been proposed that the role of Communication could be an intermediary one between IP protection and trust. If this is modeled (PLS model 2, not shown), the path coefficient between IP to Communication becomes $0.85(\mathrm{t}=14.32)$, while the path from Communication to Trust is $0.294(\mathrm{t}=22.38)$, with a model fit of $\mathrm{R}^{2}=0.88$. This model shows that IP and Communication may indeed be related, and that in fact the significance of IP protection in the model is increased.
Table $6 . \mathrm{R}^{2}$-values of performance, intellectual property (IP) protection and trust.

\begin{tabular}{ll}
\hline & $\mathrm{R}^{2}$ \\
& \\
Performance & 0.91 \\
IP protection & 0.69 \\
Trust & 0.86 \\
\hline
\end{tabular}

The relations between the trust variables and the formal and non-formal IP protection have been investigated. Only the respondents of 7 companies and 2 commercial research organizations could answer (part of) the questions, so $\mathrm{N}$ is lower than 33. Because of the central importance of IP protection, we decided to analyze the data using Spearman Rank correlation with pairwise deletion (Table 7).

A remarkable observation from Table 7 is that there is a very significant negative relation between formal and non-formal protection mechanisms. Another remarkable observation is that the level of non-formal IP protection is significantly and positively related to opportunism (more non-formal IP protection is related to more opportunism). This may imply that non-formal IP protection methods leave room for opportunism from the other collaboration partners, e.g. by abusing confidentiality arrangements.

\section{Conclusions}

It was the aim of the present study to improve our insight in the role of the interplay of prior experience, IP protection 
Table 7. Spearman rank correlation of formal and non-formal intellectual property (IP) protection vs. trust using pairwise deletion; ** $P<0.01 ; * * * P<001)$. Opportunism: non-reversed scale ( $\mathrm{n}$ between parentheses).

\begin{tabular}{lllllll}
\hline & $\begin{array}{l}\text { Non-formal IP } \\
\text { protection }\end{array}$ & $\begin{array}{l}\text { Formal IP } \\
\text { protection }\end{array}$ & $\begin{array}{l}\text { Keeping } \\
\text { promises }\end{array}$ & $\begin{array}{l}\text { Extra } \\
\text { investments }\end{array}$ & Opportunism & Cooperate again \\
$\begin{array}{l}\text { Non-formal IP } \\
\text { protection }\end{array}$ & 1.000 & $-0.498^{* *}(30)$ & $-0.243(29)$ & $0.012(29)$ & $0.685^{* * *}(25)$ & $0.049(25)$ \\
$\begin{array}{l}\text { Formal IP } \\
\text { protection }\end{array}$ & 1.000 & $0.66^{* *}(23)$ & $0.254(23)$ & $0.043(20)$ & $0.341(20)$ \\
\hline
\end{tabular}

and communication on trust and on the performance of innovation alliances. Three different relations have been proposed (Klein Woolthuis et al., 2005). The first stream, stemming from transaction cost economics, regards IP as a basis for trust, as IP arrangements make opportunistic behavior more difficult. The second view conceptualizes IP in conflict with trust, as the setting up of IP arrangements might be regarded as a sign of distrust by the partner(s); IP arrangements may then even evoke conflict. Hence it is argued that IP negatively influences the level of trust. And thirdly, there is the notion that trust precedes IP arrangements and thus decreases the need for formal arrangements; the relation is embedded in trust.

The PLS model presented in Figure 2 shows the positive impact of prior experience, IP protection, communication on trust and via trust on innovation performance in alliances. The positive relationship between prior experience and IP protection may indicate that if respondents have experienced a failed collaboration, they might be less inclined to trust possible partners again, and make more use of IP protection in new collaborations. In addition, PLS model 2 shows that IP protection and Communication may indeed be related, and that this way the significance of IP in the PLS model is increased. These results suggest that communication might indeed play an intermediary role between IP and Trust. From this we conclude, in contrast to the three possibilities suggested above, that IP Protection may provide the platform for open communication, important to build trust in an innovation alliance. A different interpretation, however, might be that more IP protection will often be related to more intense collaboration, with hence more contact, or that the security IP offers may lead to more contact, as one is more secure that the partner will not be make inappropriate use of the information. This could be an interesting topic for further investigation.

Two remarkable observations stem from Table 7. Firstly, nonformal IP protection is positively related to opportunism.
This may imply that non-formal IP protection methods leave room for opportunism from the other collaboration partners, e.g. by abusing confidentiality arrangements, while formal IP protection arrangements are positively related to the partner keeping promises, which may indicate that, apart from the influence trust may have, one's partners are more inclined to keep promises if one makes more use of formal IP protection mechanisms, maybe because they are more afraid to be taken to court. And secondly, there is a very significant negative relation between formal and non-formal protection mechanisms. This might indicate that these are not just different dimensions of an overarching concept, but completely distinct. The difference between formal and non-formal IP protection and the different influences these may have on innovation alliance performance is also an interesting topic for further investigation.

Interestingly, distrust has never been mentioned as a reason for alliance failure during the interviews, while Omta and Van Rossum (1999), who focused on failed alliances, discovered that this was the case in 7 out of 12 failed alliances. This could be caused by the fact that alliance failure is a sensitive issue. However, it could also be that there is an important phase before the alliance starts, some sort of a non-formal selection procedure in which trust plays an important role. Maybe if trust is not found or established here, the alliance does not even start. To find out how trust is built, this thus may be an important phase to investigate, as also Poppo (2013) proposed in her literature review. It could even be that this phase of getting to know each other and of writing the goals and agreements related to the alliance, are essential for building trust. This would mean that standard contracts, as some companies we interviewed used, may harm the trust building in the alliance, and thus its performance. This could explain the positive relation between alliance failure and the use of standard contracts we found in the few alliances where a failed alliance was reported (not presented in the results section). 
It is important to be aware of the limitations of the present study. As only data of 33 alliances were available there is a risk of over-fitting the data. Because of the limited amount of data it was also not possible to incorporate other factors that could play a role, such as the risk on leakage of confidential information and the complementarity between the partners. Hence the collection of more data is recommended to gain a higher external validity. Also, the measurement of different constructs deserves attention. The high latent variable correlations may point at the fact that the different latent variables have not been measured sufficiently precise, and thus do not represent the different concepts, but rather an overall satisfaction with the alliance and its performance. However, as the model confirms the relationships expected based on literature and also explains a number of failed alliances, the results of the model can be considered reliable taking these limitations into account.

\section{Recommendations}

The present study shows that for innovation performance in innovative alliances, building and maintaining trust is of critical importance. Hence it is important to find (a) partner(s) one can trust and to feed this trust with communication to let it grow even further. To start with the selection of partners; it is important not only to select on complementarity, but also on trustworthiness. As a manager you could ask yourself if you know colleagues or experts that you trust, who can give you more information about the trustworthiness of your potential partner and the incentives and the IP protection measures that may stimulate the potential partners to act trustworthy. Furthermore, it is important to understand that there is a trade-off between familiarity and novelty. Novel partners may offer new knowledge, but may be difficult to understand (due to the cognitive distance, Nooteboom, 2006). Sometimes it may thus be better to choose a partner that is slightly less complementary to your company. Related to this, it may be important not to have too many partners, as it has been reported that especially large alliances with many partners suffer from opportunism and cognitive distance. With respect to familiarity, also the business culture of the partner may be important. Fortuin and Omta (2008), for instance, report the differences in dealing with contracts and IP between European and US-based companies. In addition, as communication is important, distance may be of influence, as larger distances can be expected to lead to less contact. Especially as face-to-face contact is important; it may be advisable to choose partners that are located nearby. And if a partner is located at far distance, frequent email, skype and phone contact is recommended to be sure that no misunderstandings occur. It is also good to note that it may be worth the efforts and costs to invest in one's relation with a potential partner before the collaboration is formalized. This may make the formalization easier, shorter and thus cheaper, and may increase the mutual understanding and thus also the insights in what arrangements need to be made.

When a partner has been chosen, IP arrangements have to be set up. The present study showed that making clear arrangements is very important for collaborations, not only as a legal mechanism, but also because contracts have three additional functions: 1 . coordination; 2 . safeguard for contingencies; and 3. as a sign of commitment (Klein Woolthuis et al., 2005). It is important to realize that IP protection is never a goal in itself, but only a means towards building a secure platform on which trust can be build. Hence, the setting up of contracts and IP arrangements should be used to build trust and to foster communication. In this, ample care should be taken to adapt the use of IP arrangements to the problem complexity (Felin and Zenger, in press). Finally, it is important to understand the crucial role of flexibility and creativity in innovation. Only by allowing a certain degree of freedom in the alliance, high innovative performance can be expected. Hence IP protection should not be used to fixate all possible situations in advance, but to give direction in how to deal with certain contingencies. As one of our respondents stated: 'the best practice in collaboration is to make good arrangements in advance, but not to lay down too many things too precisely. In this way, one can switch quickly if things change or new opportunities occur'. And on our question how abuse could be prevented in such an open relation, he answered: 'by a lot of communication'.

\section{Acknowledgements}

The authors would like to thank the respondents that contributed to the research for the valuable contributions. The study received funding from the European Union Seventh Framework Program (FP7/2007-2013) under grant agreement no. 245301 NetGrow.

\section{References}

Arora, A., A. Fosfuri and A. Gambardella, 2001. Markets for technology and their implications for corporate strategy. Industrial and Corporate Change, 10(2): 419-451.

Barney, J.B. and M.H. Hansen, 1994, Trustworthiness as a source of competitive advantage. Strategic Management Journal, 15: 175-90. 
Becerra, M. and A.K. Gupta, 2003, Perceived trustworthiness within the organization: the moderating impact of communication frequency on trustor and trustee effects. Organization Science, 14(1): 32-44.

Bönte, W. and M. Keilbach, 2005. Concubinage or marriage? Nonformal and formal cooperations for innovation. International Journal of Industrial Organization, 23(3-4): 279-302.

Chesbrough, H., and R.S. Rosenbloom, 2002. The role of the business model in capturing value from innovation: evidence from Xerox Corporations technology spin-off companies. Industrial and Corporate Change, 11(3): 529-555.

Chesbrough, H.W., 2003. Open innovation: the new imperative for creating and profiting from technology. Harvard Business School Press, Boston, MA, USA.

Das, T.K. and B. Teng, 1998. Between trust and control: developing confidence in partner cooperation in alliances. Academy of Management Review, 23(3): 491-512.

Denolf, J., 2010. De rol van beschermbaarheid voor groei van hoogtechnologische starters, Master thesis University of Ghent, Belgium.

Enkel, E., O. Gassmann and H. Chesbrough, 2009. Open R\&D and open innovation: exploring the phenomenon. R\&D Management, 39(4): 311-316

Felin, T. and T.R. Zenger, in press. Closed or open innovation? Problem solving and the governance choice. Research Policy, in press: doi 10.1016/j.respol.2013.09.006.

Fortuin, F, 2007. Strategic alignment of innovation to business. Innovation and sustainability series, no. 2. Wageningen Academic Publishers, Wageningen, the Netherlands, $176 \mathrm{pp}$.

Garbade, P.J.P., F.T.J.M. Fortuin and S.W.F. Omta, $2013 a$. Coordinating clusters: a cross sectoral study of cluster organization functions in The Netherlands. International Journal on Food System Dynamics, 33: 243-257.

Garbade, P.J.P., F.T.J.M. Fortuin and S.W.F. Omta, 2013b. Exploring the characteristics of innovation alliances of Dutch biotechnology SMEs and their policy implications. Bio-based and Applied Economics, 21: 91-111.

Garbade, P.J.P., S.W.F. Omta, F.T.J.M. Fortuin, R. Hall and G. Leone, 2013c. The impact of the product generation life cycle on knowledge valorization at the public private research partnership, the Centre for BioSystems Genomics. NJAS Wageningen Journal of life sciences, 67: 1-10.

Granovetter, M., 1973. The strength of weak ties. The American Journal of Sociology, 78(6): 21.

Granovetter, M., 1983. The strength of weak ties: a network theory revisited. Sociological Theory, 1: 201-233.

Hulland, J.S., 1999. Use of partial least squares PLS in strategic management research: a review of four recent studies. Strategic Management Journal, 20: 195-204.

Klein Woolthuis, R., B. Hillebrand and B. Nooteboom, 2005. Trust, contract and relationship development. Organization Studies, 26(6): 813-840.
Larson, A., 1992. Network dyads in entrepreneurial setting - a study of the governance of exchange relationships. Administrative Science Quarterly, 37(1): 76-104.

Luo, Y., 2002. Contract, cooperation, and performance in international joint ventures. Strategic Management Journal, 23: 903-919.

MacEvily, S.K., K.M. Eisenhardt and J.E. Prescott, 2004. The global acquisition, leverage, and protection of technological competencies. Strategic Management Journal, 25(8-9): 713-22.

Narula, R. and J. Hagedoorn, 1999. Innovating through strategic alliances: moving towards international partnerships and contractual agreements. Technovation, 19(5): 283-294.

Nicholls-Nixon, C.L. and C.Y. Woo, 2003. Technology sourcing and output of established firms in a regime of encompassing technological change. Strategic Management Journal, 24(7): 651-666.

Nilsson, M., 2008. A tale of two networks: sharing resources to compete Lund studies in economics and management: Lund Business Press, Lund, Sweden.

Nooteboom, B., 2006. Trust and innovation. Tilburg University, Tilburg, the Netherlands, $12 \mathrm{pp}$.

OECD and EUROSTAT, 2005. Oslo manual - guidelines for collecting and interpreting innovation data: the measurement of scientific and technological activities, $3^{\text {rd }}$ ed. OECD Publishing, Paris, France, 162 pp.

Omta, S.W.F. and F.T.J.M. Fortuin, 2013. The effectiveness of cluster organizations in facilitating open innovation in regional innovation systems. The case of Food Valley in the Netherlands. In: Garcia, M. (ed.) Open Innovation in the Food and Beverage industry. Woodhead Publishers Ltd., Cambridge, UK, pp. 174188.

Omta, S.W.F. and W. van Rossum, 1999. The management of social capital in R\&D collaborations. In: Leenders, R.Th.A.J. and S.M. Gabbay (eds.) Corporate social capital and liability. Kluwer Academic Publishers, Boston, MA, USA, pp. 356-376.

Ozmel, U., J.J. Reuer, D. Yavuz and T. Zenger, 2013. Alliance contracts: bargaining power, network effects and value appropriation in alliances. Academy of Management Proceedings, 2013:13337.

Peck, M.J., 1986. Joint R\&D: The case of microelectronics and computer technology corporation. Research Policy, 15(5): 219231.

Poppo, L., 2013, Origins of inter-organizational trust: a review and query for future research. In: Bachman, R. and A. Zaheer (eds.) Handbook of advances in trust research. Edward Elgar Publishing, Cheltenham, UK, 336 pp.

Tepić, M., J.H. Trienekens, S.W.F. Omta and F.T.J.M. Fortuin, 2014. Governance in different types of sustainability-oriented coinnovation partnerships in the Dutch agri-food sector. In: Das, T.K. (ed.) Managing public-private strategic alliances. Information Age Publishing, Charlotte, NC, USA, pp. 189-225. 
West, J. and M. Bogers, 2013. Leveraging external sources of innovation: a review of research on open innovation. Journal of Product Innovation Management, 31(4): 1-18.

Zott, C., R. Amit and L. Massa, 2011. The business model: recent developments and future research. Journal of Management, 37(4): 1019-1042.

Burgelman, R.A. and R.S. Rosenbloom, 1997. Design and Implementation of technology strategy: an evolutionary perspective. Division of Research, Harvard Business School, Boston, MA, USA.
Sabel, C.F., 1993. Studied trust: building new forms of cooperation in a volatile economy. Human relations, 46(9): 1133-1170.

Fortuin, F.T.J.M. and S.W.F. Omta, 2008. The dark side of open innovation: a survey of failed inter-company cooperation. Proceedings of the 8th International Conference on Management in AgriFood Chains and Networks, Wageningen, the Netherlands.

\section{Appendix 1. t-values of the path coefficients of the PLS model.}

\begin{tabular}{llll}
\hline & Sample mean & Standard error & t-statistics \\
& & & \\
Prior experience -> IP protection & 0.82 & 0.12 & 7.00 \\
IP protection -> Trust & 0.39 & 0.19 & 1.91 \\
Communication -> Trust & 0.58 & 0.22 & 2.66 \\
Trust -> Performance & 0.95 & 0.03 & 35.03 \\
\hline
\end{tabular}

